\title{
Pleidooi voor een ontwerpgerichte bestuurskunde
}

\author{
Arwin van Buuren
}

\section{Inleiding}

De vraag hoe de bestuurskunde de praktijk van het openbaar bestuur beter van dienst kan zijn, houdt velen in ons vakgebied bezig (Ringeling, 2007; Van Twist, 2010; Perry, 2012). Velen maken zich zorgen over de academisering van de bestuurskunde, waarbij het vakgebied zich lijkt weg te bewegen van zijn oorspronkelijke doel en inzet. De afscheidscolumn van Wim Derksen vat deze zorgen kernachtig samen. ${ }^{1}$ Maar ook jonge hoogleraren Bestuurskunde herkennen die zorg (Karré, 2016). En niet zelden voelt een bestuurskundige zich tamelijk onbehagelijk als hij of zij gevraagd wordt het openbaar bestuur te adviseren. Dat onbehagen zien we terug in een artikel van Duncan Watts (2017) waarin hij beschrijft hoe hij zich voelt als meer natuurwetenschappelijke collega's bij IBM hem als sociaal wetenschapper vragen om te adviseren vanuit zijn vakgebied. Gelet op de grote theoretische incoherentie in dit domein is het vrijwel onmogelijk om te komen tot gezaghebbende uitspraken in de trant van 'als je dit doet, kun je dat verwachten'. Op basis daarvan pleit Watts ervoor om meer aandacht te geven aan oplossingsgericht onderzoek. Dat dwingt wetenschappers het incoherentieprobleem op te lossen en faciliteert dus wetenschappelijke vooruitgang. Maar, in zijn woorden, 'it would help social science to be more visibly useful to the world, thereby improving its status with an increasingly skeptical public, as well as generating excitement and interest among students who might otherwise choose the natural sciences, engineering or some other profession entirely' (Watts, 2017, p. 4).

Van oudsher is de bestuurskunde een praktijk- en toepassingsgerichte wetenschap. Sterker nog, het was een van de founding fathers van de bestuurskunde, Simon, die in 1969 betoogde dat een vakgebied als de bestuurskunde zich bezighoudt met een studieobject dat door mensen is vormgegeven, the artificial (en dus niet met natuurlijke objecten). Dit object, of het nu organisaties, processen, systemen of regels zijn, is vormgegeven met een doel of bedoeling. En de bestuurskunde onderzoekt in hoeverre dit object ook dit doel realiseert en hoe dit object die doelstelling eventueel beter zou kunnen realiseren. Dat maakt dat de bestuurskundige zich bezighoudt met typische ontwerpvragen: hoe een artefact zou moeten worden vormgegeven om het doel te realiseren waarvoor het bedoeld is.

De roep om meer oplossingsgericht onderzoek sluit dus naadloos aan bij een oude traditie in ons vakgebied, maar ook bij de toenemende populariteit van meer ont-

* Prof. dr. M.W. van Buuren is hoogleraar Bestuurskunde aan de Erasmus Universiteit Rotterdam.

1 Zie www.wimderksen.com/2015/05/14/afscheid-van-de-bestuurskunde/. 
werpende werkwijzen binnen en buiten het openbaar bestuur. Dat vraagt om een revitalisering van het idee van de bestuurskunde als ontwerpwetenschap. In mijn oratie schetste ik de contouren van een bestuurskundige ontwerpbenadering en sta ik stil bij de implicaties ervan (Van Buuren, 2017). In dit artikel vat ik een en ander kort samen.

\section{Een schets van het bestuurskundig ontwerpproces}

In de traditie van Simon hebben velen nagedacht over de vraag hoe de bestuurskunde als ontwerpwetenschap vorm kan krijgen. Daarin is onmiskenbaar een wetenschappelijk-analytische en rationalistische boventoon te onderkennen (Miller, 1984; Radine, 1987; Shangraw \& Crow, 1998). Dat is jammer, temeer omdat dit niet de grondtoon in de ontwerpwetenschappen zelf is. In deze wetenschappen wordt vaak betoogd dat - waar klassiek wetenschappelijk onderzoek zich prima leent voor getemde problemen - de design studies juist geschikt zijn voor meer wicked issues (Buchanan, 1992; Farrell \& Hooker, 2013). Als alle kennis beschikbaar is en het probleem eenduidig is te definiëren, is het ook niet zo moeilijk de oplossing erbij te vinden. Er is sprake van determinate (letterlijk 'be-paalde' of gestructureerde) problemen. Je zet dan alle feiten op een rij en zoekt dan naar de beste oplossing.

Maar als onzekerheid ons parten speelt en onze kennis beperkt is, als we te maken hebben met complexiteit, non-lineaire feedback en onvoorspelbare dynamiek, en als er sprake is van normativiteit en controverse over hoe het vraagstuk te interpreteren en af te bakenen, dan kun je niet alle feiten op een rij zetten. In dat soort situaties schiet het klassiek analytische arsenaal van onderzoeksmethoden tekort. Simpelweg gezegd weet je in dit soort situaties niet waar je kijken en waar je zoeken moet.

Om tot (verklarende) kennis te komen hanteren wetenschappers inductieve of deductieve redeneringen. Die zijn onderdeel van de empirische cyclus. ${ }^{2}$ Zowel deductief als inductief onderzoek noodzaakt echter dat we de werkelijkheid reduceren. Bij inductief onderzoek doen we dat door ons onderzoeksobject dat we willen bestuderen goed af te bakenen om zo tot scherpe waarnemingen en dus tot patronen te komen. Bij deductief onderzoek doen we dat door te kiezen welk stukje theorie ofwel welke hypothese we willen toetsen.

Het probleem met de vraagstukken waarmee een bestuurskundige geconfronteerd wordt, is dat ze helemaal niet zo eenvoudig af te bakenen zijn. Alles hangt met alles samen. En al die kwesties kunnen helemaal niet zo eenvoudig in de mal van een bepaald theoretisch kader worden gewrongen. Je weet niet welk perspectief je moet hanteren om recht te doen aan het issue in kwestie. In dat soort situaties schiet zowel inductie als deductie tekort, tenzij we de werkelijkheid versimpelen tot een onbeduidend deelaspect. Als we dat niet willen, moeten we op zoek naar:

2 Uiteraard kan ook de regulatieve cyclus (Van Strien, 1986) worden gehanteerd, maar in het academisch onderzoek ligt de nadruk normaliter veel sterker op toetsend of verklarend onderzoek dan op praktijkgericht onderzoek. 
1 een werkwijze die ons helpt om een beetje intelligent te gissen naar een zinvol startpunt om tot inzicht in het vraagstuk te krijgen, waarbij we ons niet beperken tot wat we reeds weten;

2 en naar een werkwijze die helpt om al uitproberend stapje voor stapje erachter te komen hoe de werkelijkheid in elkaar steekt en wat werkt.

Naar mijn overtuiging zijn het juist de ontwerpwetenschappen die daarin voorzien. Dat komt omdat ontwerpgericht onderzoek ruimte geeft aan abductie en voorziet in een werkwijze waarbij iteratief de probleem- en oplossingsruimte wordt gepreciseerd. Bij abductie wordt geprobeerd om op basis van zoveel mogelijk aanwijzingen een logische gevolgtrekking te maken. Die gevolgtrekking vormt als het ware een tijdelijk houvast en het vertrekpunt voor nader onderzoek. Het gaat dus om een intelligente gissing. Deze wordt weer schielijk ingeruild op het moment dat er een betere gissing beschikbaar is. Abductie is de werkwijze van een detective die uit alle omstandigheden en aanwijzingen een hint moet afleiden die hem op het spoor zet van de dader.

Ontwerpen is een werkwijze om via het ontwikkelen en uitproberen van een mogelijke oplossing (gebaseerd op een 'educated guess') voor een probleem inzicht te verwerven in zowel het probleem als de mogelijke oplossing. Ontwerpgericht onderzoek is dus zeker niet alleen een manier om oplossingen tot stand te brengen. Ontwerpgericht onderzoek is vooral ook een manier om al zoekend en uitproberend tot een beter begrip te komen van een complexe situatie.

Het vertalen van die kennis in een oplossing of een ontwerp dwingt de onderzoeker om te komen tot een betekenisvolle synthese van alles wat hij weet, niet alleen over het probleem en zijn oorzaken maar ook over de mogelijke oplossing en haar effecten. Die kennis wordt als het ware samengebald in een ontwerp. Het werken met een ontwerp maakt het ook mogelijk om uit te testen of de kennis die daarin is vervat ook daadwerkelijk deugt, door deze uit te proberen en te testen.

\section{Een bestuurskundige ontwerpmethodologie}

De bestuurskunde is een ontwerpwetenschap. Maar ze moet wel daadwerkelijk een ontwerpgerichte methodologie ontwikkelen om dat waar te maken. Als een bestuurskundige via een ontwerpende benadering bruikbare en valide kennis wil ontwikkelen, is het cruciaal dat hij of zij dit enerzijds 'evidence-based' doet, en dus met behulp van betrouwbare kennis en gericht op het produceren van nieuwe kennis. Anderzijds heeft het ontwerpen alleen meerwaarde als er ruimte is voor verbeelding en creativiteit: alleen dan kan er worden gegist naar een plausibele verklaring waarmee het zoekproces naar een werkende oplossing gestart kan worden (Mabsout, 2015). Steen (2013) spreekt over het combineren van inquiry en imagination: onderzoek en verbeeldingskracht. Met andere woorden: een ontwerpgerichte bestuurskunde combineert creative design met evidence-based design. Het is 'inspirational' en 'informational' (Hermus et al., forthcoming). 


\section{Figuur 1 Proeve van een bestuurskundig ontwerpproces}

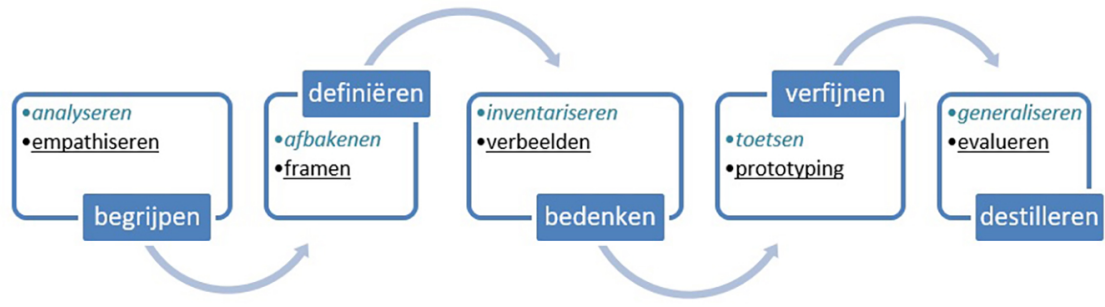

Voor dat laatste is het nodig dat de bestuurskunde haar klassieke arsenaal van wetenschappelijke en analytische methoden combineert met creatieve werkvormen om ruimte te geven aan de kracht van de verbeelding en het toepassen van waarschijnlijkheidsredeneringen (abductief redeneren). In figuur 1 presenteer ik het bestuurskundig ontwerpproces in een vijftal ronden. Per ronde kan onderscheid worden gemaakt tussen meer analytische activiteiten (cursief gedrukt) en meer creatieve (onderstreept).

\section{Empathiseren}

In elke ontwerpgerichte benadering krijgt het begrijpen van het vraagstuk en de wensen en verlangens van de betrokkenen veel aandacht. In hedendaagse benaderingen van ontwerpprocessen wordt de eerste fase geduid als 'empathizing'. Het gaat, met andere woorden, om het invoelen van het vraagstuk, het 'er gevoel voor krijgen'. Het gaat dus ook om de gevoelswaarde van het vraagstuk, de wijze waarop betrokkenen het ervaren, de emoties die zij erbij hebben.

Zowel documentstudie, interviews, focusgroepen als vragenlijsten zijn prima inzetbaar om tot een goed begrip te komen van de ontwerpopgave. Datzelfde geldt voor participerende vormen van observatie en meer etnografisch onderzoek. Ook meer eigentijdse methoden als story-telling of dagboekstudies kunnen helpen. We hebben vormen van 'appreciative inquiry' nodig: we moeten leren om op een waarderende wijze te vorsen naar wat anderen beweegt, waarom ze vinden wat ze vinden en doen wat ze doen (Argyris \& Schön, 1978; Dunne \& Martin, 2006).

\section{Definiëren}

Op basis van een grondig begrip van het vraagstuk en de context is het mogelijk de ontwerpvraag te formuleren. Dit formuleren gaat meestal gepaard met het reframen van de oorspronkelijke vraag. Achter een mobiliteitswens kan eenzaamheid schuilgaan. Een gebrek aan animo voor het aanbrengen van dakisolatie kan voortkomen uit onwil om de zolder op te moeten ruimen. Het lerarentekort is misschien wel veel minder een vraagstuk van rekrutering dan van het vasthouden en binden van leerkrachten. Een frame dat het vraagstuk goed representeert en 
tegelijk ook de weg opent naar nieuwe, onvermoede oplossingen, is vaak al de halve oplossing.

De framing van het vraagstuk is dus voor ontwerpers een cruciale activiteit, waarbij nieuwe samenhangen tussen verschillende perspectieven worden gevonden die helpen bij het vinden van een mogelijke oplossing (Kolko, 2010). Daarbij zijn werkvormen nodig die ruimte bieden aan creativiteit en verbeelding (zoals spelsimulaties, visualisaties, toekomstverbeeldingen et cetera). Ook het nadenken over mogelijke toekomsten en manieren om die te realiseren (inverse future engineering, scenariospellen) kan helpen. De kunst is om een zodanige framing van de ontwerpopgave te realiseren, dat partijen worden verleid om oude beelden opzij te zetten en nieuwe mogelijkheden te verkennen.

\section{Bedenken}

In de derde fase (al moet worden onderstreept dat een ontwerpproces iteratief en dus grillig is) staat het bedenken van mogelijke oplossingen centraal. In deze fase wordt een groot beroep gedaan op zowel de ambachtelijkheid als de creativiteit van de ontwerper. Het out-of-the box-nadenken over mogelijke oplossingen kan alleen als er ruimte is voor improvisatie en speelsheid (Schön, 1993; March, 1971) en wanneer de ontwerper openstaat voor verrassingen en onverwachte gezichtspunten. Creativiteit heeft alles te maken met het bewust binnenhalen van het onverwachte, het onbekende en het ongerijmde, juist omdat zo de oplossingsruimte wordt vergroot, en dus de kans op een werkbaar prototype. Tegelijk kan het benutten van conceptuele kennis of van ervaringen uit andere contexten ter inspiratie en vergelijking nuttig zijn. Juist op die manier wordt het ontwerpgericht onderzoek ook evidence-based: het maakt gebruik van inzichten en lessen die gedestilleerd worden uit ervaringen elders en eerder.

\section{Verfijnen}

In deze ronde komt het erop aan dat het systematisch proberen een nadere uitwerking krijgt. In hedendaagse benaderingen rond 'design-thinking' wordt dan gesproken over rapid prototyping: het snel uitproberen van voorlopige ideeën en het op deze wijze komen tot een steeds betere benadering van de uiteindelijke oplossing. Maar dit verfijnen kan ook meer systematisch, door grondig te observeren, wat een interventie of verandering teweegbrengt. Soms zijn er zelfs mogelijkheden voor een meer experimentele aanpak, waarbij in de ene situatie de interventie wordt toegepast en in de andere situatie niet. Hier kan de recent ontwikkelde aanpak van design experimenten goede diensten bewijzen (Stoker \& John, 2009; Askew et al., 2010). Deze zijn in potentie een krachtige combinatie van rigour en relevance en verdienen in de bestuurskunde veel meer aandacht dan ze tot nu toe krijgen. Ze geven invulling aan datgene wat collega Van der Steen (2016) zo mooi benoemd heeft als 'systematisch uitproberen'.

\section{Destilleren}

Tot slot moet uit de veelheid van de ervaringen en lessen datgene worden gedestilleerd dat de moeite waard is om te behouden. In het klassieke ontwerpdenken wordt veelal gestreefd naar een ontwerp dat fungeert als basis voor verdere 
productontwikkeling. In het bestuurskundig ontwerpen gaat het daarentegen vaak om meerdere prototypen of om uiteenlopende bouwstenen voor een prototype, die als basis dienen om te komen tot maatwerk in een andere situatie, met gevoel voor de context. Dit zijn als het ware verschillende grondvormen of sjablonen, die afhankelijk van de context een nadere invulling kunnen krijgen. Deze fase leidt dus uiteindelijk tot een concreet ontwerpresultaat, waarmee de probleemeigenaar verder kan en die ook als basis kan dienen voor toepassing elders. Tegelijkertijd gaat het in de fase van het destilleren ook om het ophalen van de wetenschappelijke oogst van het ontwerpproces. Immers, het ontwerpproces is ook een manier om stapsgewijs en al uitproberend inzicht te verwerven in een complexe thematiek. Dat betekent dus ook dat in de afrondende fase van een ontwerpproces de vraag beantwoord wordt, welke meer generaliseerbare kennis opgedaan is. Zoals we straks nog zullen zien, kan abductief denken niet zonder deductie en inductie en zijn er in deze fase juist kansen voor meer systematische kennisontwikkeling.

\section{Discussie en reflectie}

De bestuurskunde is gebaat bij een ontwerpmethodologie die ons in staat stelt een bijdrage te leveren aan het oplossen van maatschappelijke vraagstukken en die ons tegelijkertijd helpt om een beter inzicht te krijgen in die vraagstukken en in de vraag hoe deze opgelost zouden kunnen worden (Van Buuren et al., forthcoming). Ontwerpen en onderzoeken gaan dan ook hand in hand. Het was Arthur Ringeling die in zijn afscheidsrede (2007) al verzuchtte dat de bestuurskunde nu echt eens werk moest gaan maken van een deugdelijke ontwerpmethodologie.

Een ontwerpgerichte insteek past bij de prescriptieve ambitie die de bestuurskunde altijd heeft gehad. Het past ook in de toenemende roep om maatschappelijk relevant te zijn als wetenschap. $\mathrm{Nu}$ mag die relevantie natuurlijk nooit ten koste gaan van of uitgeruild worden tegen wetenschappelijke kwaliteit. De kunst is dan ook om een ontwerpbenadering te ontwikkelen die niet alleen praktisch relevante ontwerpen oplevert, maar ook tot wetenschappelijk valide kennis leidt, juist door het combineren van het ontwikkelen en evalueren van interventies en het beantwoorden van de vraag waarom iets werkt of niet.

Een ontwerpgerichte bestuurskunde roept uiteraard nieuwe vragen op. Immers, de ontwerpwetenschappen geven een belangrijke rol aan zaken als creativiteit, intuïtie en verbeeldingskracht. Dat zijn zaken die niet zomaar in te passen zijn in de gebruikelijke onderzoeksbenaderingen van de bestuurskunde. Dit vraagt dus om een serieuze doordenking van de vraag hoe we wetenschappelijke en maatschappelijke validatie kunnen combineren in hetzelfde proces van ontwerpgericht onderzoek. Met andere woorden, hoe we de creatieve kracht die ontwerpers weten te mobiliseren kunnen verbinden met de analytische kracht van de meer traditionele wetenschapsgebieden. Met die uitdaging wil ik me de komende jaren graag bezig gaan houden. Dat past uitstekend in de traditie die de Rotterdamse bestuurskunde van meet af aan heeft gekenmerkt: een sterke oriëntatie om de 
praktijk van het openbaar bestuur te verbeteren, met de ambitie om daar het vakgebied mee te vernieuwen en te verdiepen.

\section{Literatuur}

Argyris, C., \& Schön, D. (1978). Organizational learning: A theory of action perspective. Reading, MA: Addison-Wesley.

Askew, R., John, P., \& Liu, H. (2010). Can policy makers listen to researchers? An application of the design experiment methodology to a local drugs policy intervention. Policy \& Politics, 38(4), 583-598.

Buchanan, R. (1992). Wicked problems in design thinking. Design Issues, 8(2), 5-21.

Buuren, M.W. van. (2017) Vormgeven aan uitnodigend bestuur: Pleidooi voor een ontwerpgerichte bestuurskunde. Rede Erasmus Universiteit Rotterdam. 's-Gravenzande: Van Deventer.

Buuren, M.W. van, J.M. Lewis, B.G. Peters, W. Voorberg, (forthcoming). Improving public policy and administration - exploring the potential of design. Policy \& Politics (in press).

Dunne, D., \& Martin, R. (2006). Design thinking and how it will change management education: An interview and discussion. Academy of Management Learning and Education, 5(4), 512-523.

Farrell, R., \& Hooker, C. (2013). Design, science and wicked problems. Design Studies, 34(6), 681-705.

Hermus, M., M.W. van Buuren, V.J.J.M. Bekkers (forthcoming). Applying design in public administration - a literature review to explore the state of the art. Policy \& Politics (in press).

Karré, P.M. (2016). Bouwen aan de ideale bestuurskunde. Bestuurskunde, 25(2), 79-89.

Kolko, J. (2010). Abductive thinking and sensemaking: The drivers of design synthesis. Design Issues, 26(1), 15-28.

Mabsout, R. (2015). Abduction and economics: The contributions of Charles Peirce and Herbert Simon. Journal of Economic Methodology, 22(4), 491-516.

March, J.M. (1971). The technology of foolishness. In J.G. March (Ed.), The pursuit of organizational intelligence (1988). New York: Basil Blackwell.. 254-265.

Miller, T. (1984). Public sector performance: A conceptual turning point. Baltimore: Johns Hopkins University Press.

Perry, J.L. (2012). How can we improve our science to generate more usable knowledge for public professionals? Public Administration Review, 72(4), 479-482.

Radine, L.B. (1987). Organization theory in administrative law: A proposal for a design science. The American Sociologist, 18(3), 278-283.

Ringeling, A. (2007). Tussen distantie en betrokkenheid: Een bericht aan de tovenaarsleerlingen. Afscheidsrede Erasmus Universiteit Rotterdam.

Shangraw, R.F., \& Crow, M.M. (1998). Public administration as a design science. International Journal of Public Administration, 21(6-8), 153-160.

Simon, H. (1969). The sciences of the artificial. Cambridge: The MIT Press.

Steen, M. (2013). Co-design as a process of joint inquiry and imagination. Design Issues, 29(2), 16-28.

Steen, M. van der. (2016). Tijdig bestuur: Strategisch omgaan met voorspelbare verrassingen. Den Haag: NSOB.

Stoker, G., \& John, P. (2009). Design experiments: Engaging policy makers in the search for evidence about what works. Political Studies, 57(2), 356-373. 
Strien, P.J. van. (1986). Praktijk als wetenschap: Methodologie van het sociaal-wetenschappelijk handelen. Assen: Van Gorcum.

Twist, M.J.W. van. (2010). Over (on)macht en (on)behagen in de beleidsadvisering. Den Haag: Lemma.

Watts, D. (2017). Should social science be more solution-oriented? Nature Human Behaviour, 1, 0015. 